\title{
Towards a coherent multi-level framework for resource
}

\section{accounting}

Melissa Yuling Leung Pah Hang ${ }^{1}$, Elias Martinez-Hernandez ${ }^{2}$, Matthew Leach ${ }^{1}$, Aidong

$$
\text { Yang, }^{2 *}
$$

${ }^{1}$ Centre for Environmental Strategy, University of Surrey, Guildford, GU2 7XH, UK

${ }^{2}$ Department of Engineering Science, University of Oxford, Oxford, OX1 3PJ, UK

Address correspondence to:

*Dr Aidong Yang, Department of Engineering Science, University of Oxford, Oxford, OX1 3PJ, UK, Ph: +44 1865273094, e-mail: aidong.yang@eng.ox.ac.uk

\section{Keywords}

Cumulative exergy consumption, resource algebra, multilevel analysis, productionconsumption, bioethanol, supply chain

\begin{abstract}
With increasing resource scarcity and environmental impacts resulting from inefficient resource utilisation, accounting for resource consumption along the life cycle of a product or service becomes critical for designing production-consumption systems. This work aims at developing a coherent framework for resource accounting to support the evaluation of alternatives for production and consumption activities. The framework provides an understanding of resource utilisation at unit, process, inter-process and productionconsumption levels within a system. The multilevel characteristic of this framework allows a comprehensive and holistic view of a system with the potential to reveal how decisions at one level would affect other levels of the system. Based on such a multilevel view, a unique
\end{abstract}


adaptation of the Cumulative Exergy Resource Accounting method is proposed to quantify resource consumption associated with both technological and natural processes. This work also differentiates between and accounts for the operational resource consumption in resource extraction, agriculture and manufacturing and for the capital resource consumption for providing machinery and infrastructure. This is a practical framework for resource accounting that can be used by process engineers and local planners to support decision making regarding alternative system designs, gain insights on the performance of a production system and devise design options including retrofits for improving the overall resource efficiency of a system. By unfolding the resource consumption through each system layer, the framework provides a robust and transparent way to capture effects of decision making during design or retrofitting of processes in order to find the most efficient design options. In addition, the framework can also be applied to support research in other areas such as social, cultural and business. Finally, a case study on the production and consumption of sugarcane ethanol is used to illustrate the features of the proposed framework. The framework proved useful in assessing the effects on resource consumption for design decisions at the various levels, such as choosing between molecular sieve and azeotropic distillation at the unit level, adoption of water intra-recycling at the process level, and bagasse exchange flows at inter-process level. The proposed systematic approach has given powerful insights into how changes in resource consumption occur at different levels.

\section{Introduction}

Natural resources are the ultimate source of all the goods and services to meet human needs (e.g. food, energy, water). With world population reaching 7 billion people (USCB, 2013) and overall standards of living rising, there is inevitably a subsequent increase in the consumption of natural resources. There are mounting concerns that the supply of key 
resources such as energy, water and materials would be insufficient to meet the needs of a rising world population. Resource scarcity has also led to some commodity prices to rise significantly while depleting fossil fuels have the potential to lead to soaring oil prices (Krautkraemer, 2005). Furthermore, inefficient use and over-exploitation have adverse impacts on the local environment and contribute to climate change (Allwood et al., 2011; Huijbregts et al., 2010). In this context, improving resource efficiency by producing, processing and consuming Earth's limited resources in a sustainable manner while minimising impacts on the environment from the overall life cycle of the resource (UNEP, 2012) can bring significant economic benefits and boost competitiveness (EC, 2013). Appropriate tools and techniques are required for the realisation of these benefits. Resource accounting becomes thus an important approach that can be used to assist decision making and system design, gain insights on the performance of a production system and devise options for improving resource efficiency in order to optimise utilisation of available resources while minimising impacts on the environment. By monitoring and assessing resource consumption, the effect of retrofitting or introducing a new component into a system can be analysed and can serve as a guide for the selection of those components that improve the performance of a system.

Extensive work has been done on resource accounting, including particularly those studies based on exergy as reviewed by Gaudreau (2009). Exergy, defined as the maximum available energy to do useful work, is a thermodynamic measure of energy quality and a more insightful indicator of resource consumption as compared to energy and mass (Amini et al., 2006). It is a universal quantity that can represent a wide range of material and energy streams, the contribution of non-energetic resources (e.g. labour), ecological products and services (Hau and Bakshi, 2004) and the environmental impacts of pollutants (Jorgensen, 1997) as opposed to mass and energy based methods (Ukidwe and Bakshi, 2004). The most 
widely acknowledged exergy based methods for resource accounting which adopt a Life Cycle Assessment (LCA) approach include (a) Cumulative Exergy Consumption (CEC) by Szargut et al. (1988) which accounts for the material and energetic exergy resource inputs from extraction to industrial manufacture of the product/service, (b) Industrial Cumulative Exergy Consumption (ICEC) which is similar to CEC but focuses on industrial systems (Ukidwe and Bakshi, 2007; Zhang et al., 2010), (c) Extended Exergy Accounting (EEA) which is an extension of Szargut's CEC and additionally accounts for non-energetic resources such as money, labour and environmental remediation costs for zero environmental impact by technological processes (Sciubba, 2001), (d) Ecological Cumulative Exergy Consumption (ECEC) which is based on ICEC but extends its boundary to account for the total exergy consumed in ecological processes for the production of natural resources as well as for assimilating pollutants (Hau and Bakshi, 2004) using the concepts of emergy (Odum, 1996) and (e) Cumulative Exergy Extraction from the Natural Environment (CEENE) developed by Dewulf et al. (2007) which offers a more comprehensive accounting of all natural resources including land use; the latter has been overlooked in the other resource accounting methods. More recent applications of exergy based methods include its use in LCA to assess alternative soil remediation technologies (Rocco et al., 2015), attempts to include economic and environmental factors in ECEC of industrial processes (Yang et al., 2015) and the extension of the classical Economic Order Quantity (EOQ) model to include sustainability factors such as labour, capital and environment based on EEA approach (Jawad et al., 2014).

Besides, previous studies especially those by Hau and Bakshi (2004), Yi et al. (2004) and Liao et al. (2012) have recognised the need for a multilevel analysis for resource accounting, based on exergy and with emphasis on the system boundary, as opposed to a narrow analysis focused on individual processes which might shift the resource consumption impacts to other parts of the value chain of the product or service. Additionally, a methodological framework 
has also been developed by Hanes and Bakshi (2015a, 2015b) to address analyses at different scales. However, the existing studies do not offer a detailed multilevel analysis of the processes and flows pertaining to resource consumption at the various levels of a particular system. Such analysis is required to reveal how a resource, before and after being processed at different stages, flows within the system, which is essential for the identification of potential synergistic integration with flows linked to other products or services in the system. Furthermore, previous studies have not focused on a holistic quantitative study encompassing at the same time ecosystems (i.e. natural processes), production, and consumption of desired product or service (i.e. human systems). In particular, the consumption side of a product or service has largely been overlooked. Additionally in terms of scope it can be observed that the resource burdens of constructing plant, equipment and machineries have also been largely overlooked in existing resource accounting methods, with the importance of quantitatively accounting for these resources rarely studied. Finally, while the most recent studies on resource accounting have attempted to include a wide range of resources, the admissibility of the inclusion of money and potential double-counting of labour and money resources are still highly controversial (Rocco et al., 2013).

This work will attempt to address the above shortcomings by proposing a coherent framework for resource accounting. Conceptually, a framework that articulates the key aspects such as system boundary, types of flows and processes, principles for determining resource consumption to avoid ambiguity and double-counting, and multiple levels of analysis will be presented. Building on the conceptual framework, a quantitative approach to resource accounting based on the concept of cumulative exergy consumption will be described. The scope of the proposed framework is to assess resource consumption from a technical perspective and aims to provide support for decision making at the technical level of interest to process engineers and inform decision-makers in industry, government or non- 
government organisations particularly for the purpose of strategic planning, product design or redesign. In addition, it also has the potential to provide solid "physics” to support future research that focuses on the social, political, cultural and business aspects of this area, as well as wider environmental and economic performance. One of the major limitations of the approach is the uncertainty associated with the cumulative exergy of the data used. Data uncertainty appears to be a common limitation to holistic approaches to resource assessment (Brown and Ulgiati, 2010; Yang et al., 2010). In a practical application, it may be addressed by a careful combination of quality sources of cumulative exergy consumption data, possibly supplemented by other types of data sources such as LCA databases. Besides, this approach currently does not take into account the full range of environmental impacts such as climate change effects, toxicity and impacts of monoculture on biodiversity and offers no indication on resource depletion. However, by combining the proposed system characterisation and modelling of resource flows with other approaches such as LCA, the wider environmental implications of a system can be assessed. These limitations must be considered when interpreting the results obtained from this approach. The proposed framework will be demonstrated through a case study on the production and consumption of sugarcane bioethanol.

\section{Materials and methods}

The approach developed in this work has three main parts, comprising (i) a conceptual framework for characterising a system, (ii) a multilevel structure that supports the development of a coherent and transparent resource accounting and (iii) the formulation of resource accounting algebra for the quantitative assessment of resource consumption at the different levels. These parts are explained respectively in sections 2.1, 2.2 and 2.3, and a summary of the key elements of the framework is given in section 2.4. 


\subsection{Conceptual framework for resource accounting}

A system to which resource accounting is applied is defined by (i) the resource-embedded incoming flows that enter the system from its environment, (ii) the process or processes that convert the flows from the environment and (iii) the outgoing flows produced by the process(es) that leave the system and enter its environment. These three components of the system can be compared respectively to the input (i.e. product, material or energy flow) that enters a unit process (ISO, 2006), process which is defined as a set of interrelated activities that converts inputs into outputs (ISO, 2005) and output (i.e. product, material or energy flow) that leaves a unit process (ISO, 2006) in accordance with LCA principles. Resource accounting can be carried out within various system boundaries. In this work, the system boundary suitable for a given resource accounting task is defined according to the range of human decisions to be made based on the outcome of resource accounting. More specifically, the boundary of the system that should be considered is one that comprises only those human-driven and natural ecosystem processes which can potentially be affected by human decisions to be made in connection with this resource accounting task so as to avoid unnecessary complexity while maintaining consistency. Following this principle, a process will be excluded from the system if it occurs independently from human intervention at the level of the decisions considered, no matter whether it is completely unaffected by any human intervention (e.g. formation of coal) or only unaffected by local decisions (e.g. distant manufacturing of goods to be imported by the locale under study). Such processes essentially form the environment of the system for which resource accounting is to be carried out. In order to facilitate the subsequent discussions in this article, processes which in principle can be affected by human decisions will be referred to as Type-I processes while those that are not affected by any human decisions will be referred to as Type-II processes. Thus, the resource consumption of a system can be accounted for by aggregating the resource contents 
of all the flows which enter various (Type-I) processes within the boundary of the system. These flows themselves may be produced by either Type-I or Type-II processes outside the system; their resource contents are calculated according to the principles introduced below.

\subsubsection{Resource flows and their accounting principle}

The input flows considered for a system from Type-I and Type-II processes include material and energy flows from both natural and technological processes as well as human labour. Material and energy flows from Type-I processes are accounted for by their cumulative exergy consumption (CEC). CEC is the sum of exergy of all resources consumed along the supply chain to deliver the material or energy product under consideration; in line with the definition of CEC by Szargut et al. (1998). Labour is also accounted by its CEC; a frequently adopted estimation approach is one based on an exergy to labour conversion factor (Kotas, 1985; Sciubba, 2001; Wall, 2002) though limited by reliable data for working hours and skilllevel parameters (Yang et al., 2015).

In contrast to ECEC (Hau and Bakshi, 2004; Odum, 1996) and CEENE (Dewulf et al., 2007), the CEC of the ecological processes required for the original formation of input flows from these Type-II processes such as fossil fuels and ores will not be accounted for as they occur independently from human intervention. Instead, their exergy content and any further exergy consumption for their extraction and processing will be accounted for. Similarly, the CEC of the ecological processes for the formation of wind and solar radiation (sunlight) will not be taken into consideration. In addition, although renewables are often differentiated from nonrenewables by not accounting for their exergy inputs (Wall, 2011), our framework does consider the resource value (in the form of exergy content) of these renewables instead of treating them as "free" resources, to recognise the fact that these resources, like fossil fuels and ores, in principle have alternative uses. 
Compared to the EEA developed by Sciubba (2001), money will not be considered in this framework directly as an exergy resource flow to the system. This is because only resource flows that have a physical content and can be physically quantified will be considered in this study. On the other hand, money can be used as a basis to estimate the CEC associated with physical resource flows which are difficult to estimate directly. For example, the CEC for manufacturing and provisioning of equipment (e.g. agricultural machinery, chemical reactors, wind turbines, solar panels) can be estimated indirectly by using their capital cost if determining their CEC directly becomes too cumbersome and impractical. This assumes a direct correlation between economic costs and resource consumption (Hau and Bakshi, 2004).

\subsubsection{Resource consuming processes}

An overall depiction of the environment and the resource consuming processes occurring in the system is shown in Figure 1. In this work, the system is the part of the society over which resource accounting is conducted. It consists of two main subsystems namely the product provision subsystem and the product consumption subsystem. The product provision subsystem comprises all the processes that are required to manufacture a product or service. A process represents a sequence of processing units which can produce at least one final product or intermediate products that can be further processed by other temporally and/or spatially separate processes. 


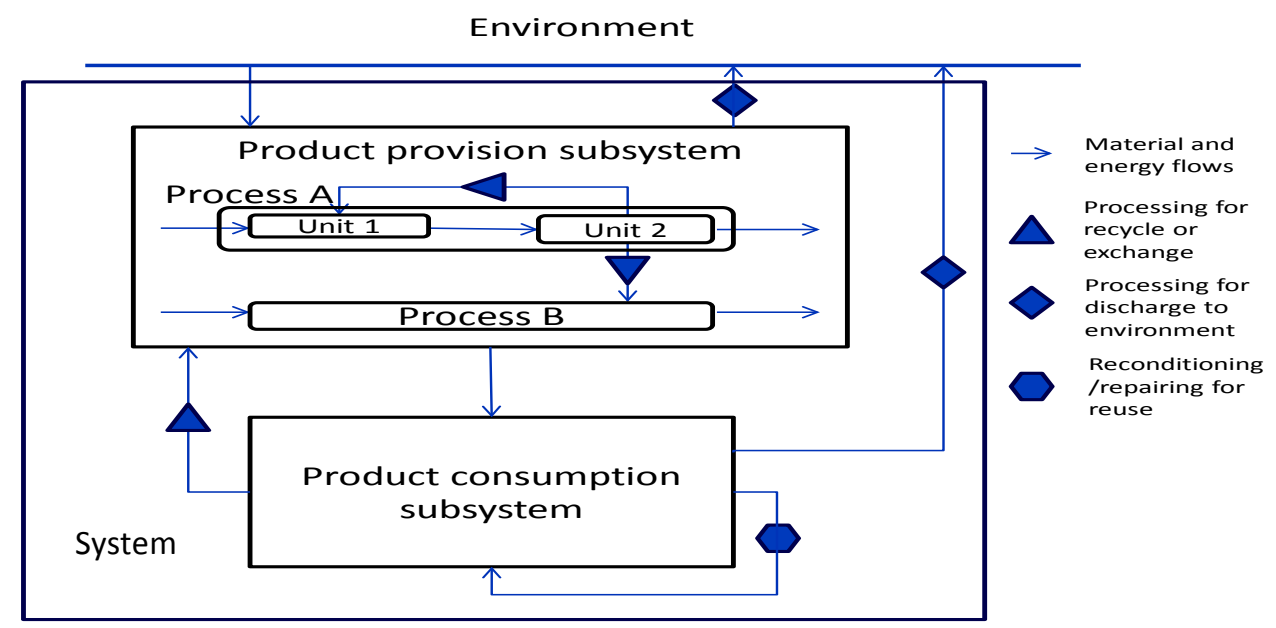

Figure 1: Overall representation of the Environment and System

The processes occurring in the product provision subsystem can be categorised as flow making, capacity making and transport and storage processes. Flow making processes include resource extraction, agriculture and industrial processes which eventually deliver the products for consumption and also provide for the energy and materials required by all types of processes in the system. These processes encompass the processes that are usually taken into consideration for an LCA (Guinée et al., 2002). When resource extraction processes are part of the system, the total exergy consumption will be the aggregation of exergy content of the resource in its original form and the exergy consumption from extraction to the point of the process unit where the resource is used. Capacity making processes are the industrial systems that provide machineries, equipment and consumables other than feedstock (e.g. catalysts) to enable flow making and transport and storage components. In this study, capital resources will refer to all resource consumption for capacity making processes while operating resources will be the resources that are used directly to operate the flow making processes for the production of the desired flows. Capital goods have often been excluded in many life cycle approach studies due to limited data (Moller, 2010), and greenhouse gas emissions from capital goods are excluded according to PAS 2050 (BSI, 2008). As part of a 
holistic resource accounting, capital resources are included in this framework as a recognised category of resource expenditure, to avoid the omission of any significant resource consumption on capital goods in certain applications. Transport and storage processes serve both flow and capacity making processes and acts as the interface between the product provision subsystem and the product consumption subsystem.

Flow recycling is a resource consuming process where recycle of materials consumed by capacity making and transport and storage to flow making can exist. Flows can also be exchanged between the different processes based on the concepts of industrial symbiosis (Chertow, 2007). The exchanged flows might need to be processed before being used as input flows to other processes, hence consuming resources. Based on the specific function of a product and its fate after consumption, the used product from the product consumption subsystem can potentially either be repaired or recycled back into the product provision subsystem. For instance, a car or a washing machine is a typical example of a product whose life can be extended through repair. In comparison, ethanol fuel is a product that will simply be converted into a different chemical form during its consumption, where repairing or recycling is inapplicable. In addition, some products like plastics and glass will be degraded during consumption but can be treated so that they can be re-used or recycled (Amini et al., 2006) and some others like bagasse can be treated for recovery of resources and production of valuable resources such as energy (DEFRA, 2014).

The environmental impacts in most studies related to cumulative exergy consumption of industrial processes have often not been considered (Hau and Bakshi, 2004; Baral et al., 2012). To overcome this, the environment remediation processes (natural or technological) for treating pollutants before they are released into the environment also form part of the system. The environmental remediation resource consumption is defined in this work as the total exergy consumption of all the environmental remediation processes required to treat the 
pollutants to the extent that, in principle, no harm is made to the environment, or, in practical terms, a certain set of environmental regulations are met.

\subsection{Multilevel structure of a system}

In an attempt to provide a better understanding of a system and support the development of a resource accounting method, a system is conceptualised as a hierarchical structure with the following levels:

- Unit level which involves a single conversion step where input to the unit is processed to output with no recycle and reuse involved. This will allow detailed analysis to be done at a scale as small as a unit operation. The smallest scale considered is often that of individual equipment, which may be part of an individual industrial process such as a chemical plant.

- Process level which comprises one or more units where intra-process (i.e. inter-unit) recycling and reuse can occur.

- Inter-process level with exchange of flows between two or more processes and reflects the principles of industrial ecology.

- Production-consumption level with reuse and recycle of products; this level includes consumption processes which have been largely neglected in existing resource accounting studies.

The quantification of resource consumption may be different at each system level, depending on the processes and arrangements with regard to recycling, exchange and repair. At each level, different key decisions can be made. At the unit level, decision making would involve choosing the most appropriate and resource efficient unit operation. At the process level, the focus of decision is on selecting the best process design to adopt. At the inter-process level, resource accounting will give an indication of the industrial synergies to promote or adopt. At 
the production-consumption level, it can identify links between production processes, the ecosystem and consumption of society with the aim of achieving a cradle to cradle resource model (Ellen Macarthur Foundation, 2013), hence as an implementation of the concept of circular economy.

\subsection{Resource accounting algebra}

Following the conceptual framework for resource accounting, a quantitative assessment of resource consumption at each of the levels is proposed in this section. The general resource accounting equation that can be applied to each system level can be expressed as:

Total resource consumption $=$ total operating resource consumption + total capital resource consumption + total resource consumption for environmental remediation (1)

In Equation (1), the resource consumption is expressed in terms of exergy. The embedded resource consumption of flows from Type-I processes (defined in section 2.1) will be accounted by the cumulative exergy consumption incurred during their production. Flows resulting from Type-II processes (defined in section 2.1) will be accounted for by their respective exergy content to acknowledge that they have alternative competing uses.

\subsubsection{Resource accounting at unit level}

Figure 2 is a simple representation of the unit level comprising the unit itself as well as the remediation process for treating any pollutant and waste streams produced by the unit. Remediation can be achieved by technological or natural processes to a level which is harmless to the environment or within limits set by environmental regulations before they are released to the environment. 


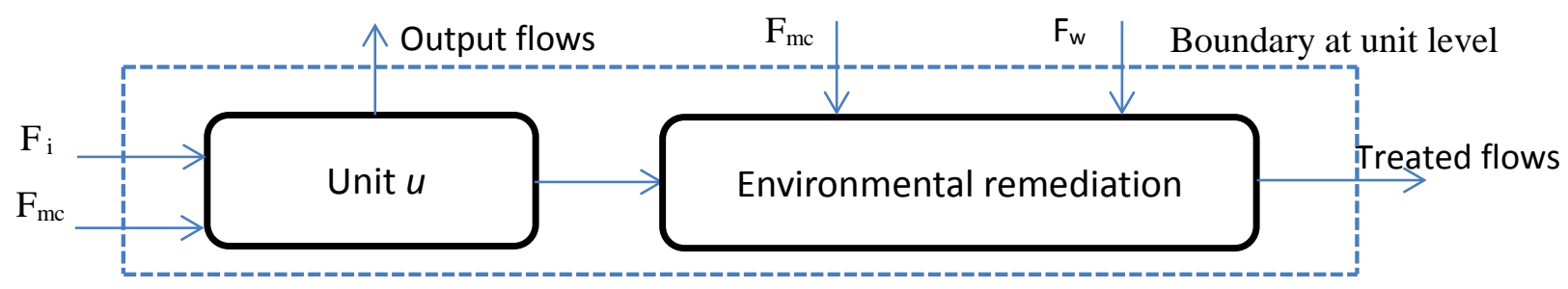

Figure 2: A representation of the unit level

Consider unit $u$ from Figure 2, the total exergy consumption by this unit $\left(\mathrm{ExC}_{\mathrm{u}}\right)$ for the production of the desired output flow is the sum of three elements: (i) total exergy consumption of its inputs $i=1$ to $I$, each with $\overline{\mathrm{ExC}}_{\mathrm{i}}$ as its specific cumulative exergy content, representing resource consumptions by flows from upstream units and operating resources $\left(\sum_{i=1}^{I} \overline{E x C}_{i} F_{i}\right)$, (ii) total exergy consumption for providing the capital resources $m c=1$ to $M C$ for unit $\underline{u}\left(\sum_{\mathrm{mc}=1}^{\mathrm{MC}} \overline{\mathrm{ExC}}_{\mathrm{mc}} \mathrm{F}_{\mathrm{mc}}\right)$ and (iii) total exergy consumption for all the environmental remediation processes associated with unit $u\left(\sum_{\mathrm{w}=1}^{\mathrm{W}} \overline{\operatorname{ExC}}_{\mathrm{w}} \mathrm{F}_{\mathrm{w}}\right)$, as given algebraically in Equation (2).

$$
\mathrm{ExC}_{\mathrm{u}}=\sum_{\mathrm{i}=1}^{\mathrm{I}} \overline{\operatorname{ExC}}_{\mathrm{i}} \mathrm{F}_{\mathrm{i}}+\sum_{\mathrm{mc}=1}^{\mathrm{MC}} \overline{\operatorname{ExC}}_{\mathrm{mc}} \mathrm{F}_{\mathrm{mc}}+\sum_{\mathrm{w}=1}^{\mathrm{W}} \overline{\operatorname{ExC}}_{\mathrm{w}} \mathrm{F}_{\mathrm{w}}
$$

\subsubsection{Resource accounting at process level}

The process level is represented in Figure 3 which illustrates a process with two units and intra-process recycling. 


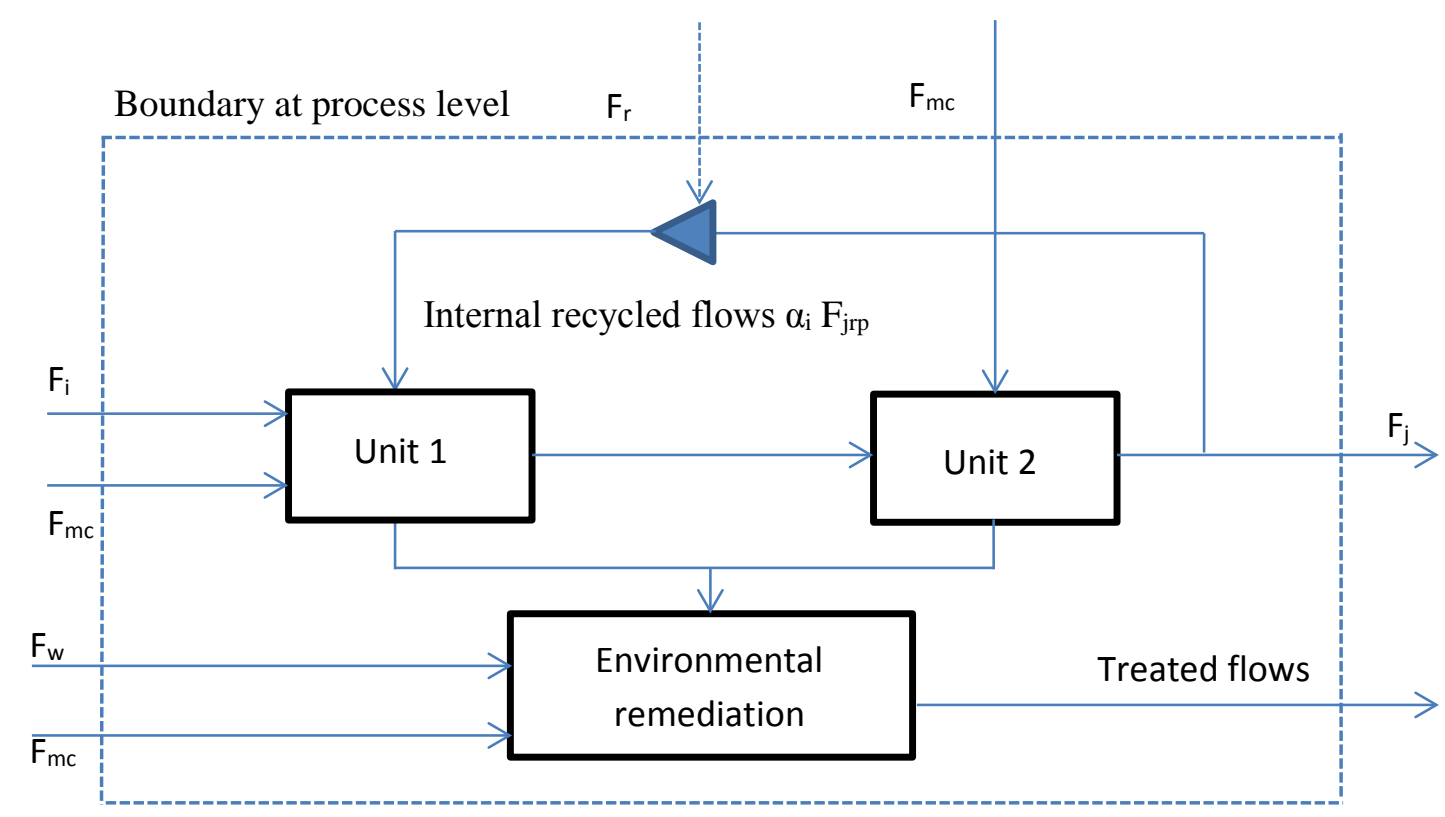

Figure 3: A representation of the process level

The total exergy consumption accounting for producing the desired flows at the level of process $p\left(\mathrm{ExC}_{\mathrm{p}}\right)$ can be determined by the difference between (i) the sum of the total exergy consumption of all units $u=1$ to $\mathrm{U}\left(\sum_{\mathrm{u}=1}^{\mathrm{U}} \mathrm{ExC}_{\mathrm{u}}\right)$ and total exergy consumption of all the flows required to process the internal recycling flows $r=1$ to $\mathrm{R}\left(\sum_{\mathrm{r}=1}^{\mathrm{R}} \overline{\mathrm{ExC}_{\mathrm{r}}} \mathrm{F}_{\mathrm{r}}\right)$ and (ii) the sum of the total exergy consumption of all the intermediate flows $i m=1$ to IM $\left(\sum_{\mathrm{im}=1}^{\mathrm{IM}} \overline{\operatorname{ExC}_{\mathrm{Im}}} \mathrm{F}_{\mathrm{im}}\right)$, total exergy consumption associated with all the fresh input flows replaced by the recycled input flows ir $=1$ to IR $\left(\sum_{\mathrm{ir}=1}^{\mathrm{IR}} \overline{\operatorname{ExC}_{\mathrm{rr}}} \mathrm{F}_{\mathrm{ir}}\right)$ and total exergy consumption of all the flows $a c=1$ to AC that would have been required for treating flows to be discharged to the environment if they were not recycled $\left(\sum_{\mathrm{ac}=1}^{\mathrm{AC}} \overline{\mathrm{ExC}_{\mathrm{ac}}} \mathrm{F}_{\mathrm{ac}}\right)$. The resource accounting algebra at process level is expressed in Equation (3).

$\mathrm{ExC}_{\mathrm{p}}=\sum_{\mathrm{u}=1}^{\mathrm{U}} \mathrm{ExC}_{\mathrm{u}}+\sum_{\mathrm{r}=1}^{\mathrm{R}} \overline{\mathrm{ExC}_{\mathrm{r}}} \mathrm{F}_{\mathrm{r}}-\sum_{\mathrm{im}=1}^{\mathrm{IM}} \overline{\mathrm{ExC}_{\mathrm{Im}}} \mathrm{F}_{\mathrm{im}}-\sum_{\mathrm{ir}=1}^{\mathrm{IR}} \overline{\mathrm{ExC}_{\mathrm{lr}}} \mathrm{F}_{\mathrm{ir}}-\sum_{\mathrm{ac}=1}^{\mathrm{AC}} \overline{\mathrm{ExC}_{\mathrm{ac}}} \mathrm{F}_{\mathrm{ac}}$

From Equation (3), the resource benefit of process recycling, $\eta_{\mathrm{pr}}$, can be expressed as the ratio of (i) the sum of the total exergy consumption of all the fresh input flows replaced by the recycled input flows and the total exergy consumption that might be required for treating 
the flow before discharging if there was no process recycling arranged, to (ii) the total exergy consumption of recycling as shown in Equation (4):

$$
\eta_{\mathrm{pr}}=\frac{\sum_{\mathrm{ir}=1}^{\mathrm{IR}} \overline{\mathrm{ExC}_{\mathrm{rr}}} \mathrm{F}_{\mathrm{ir}}+\sum_{\mathrm{ac}=1}^{\mathrm{AC}} \overline{\operatorname{ExC}_{\mathrm{ac}}} \mathrm{F}_{\mathrm{ac}}}{\sum_{\mathrm{r}=1}^{\mathrm{R}} \overline{\operatorname{ExC}_{\mathrm{r}}} \mathrm{F}_{\mathrm{r}}}
$$

\subsubsection{Resource accounting at inter-process level}

A schematic representation of the inter-process level with two processes is shown in Figure 4 with recycling as well as exchange flows.

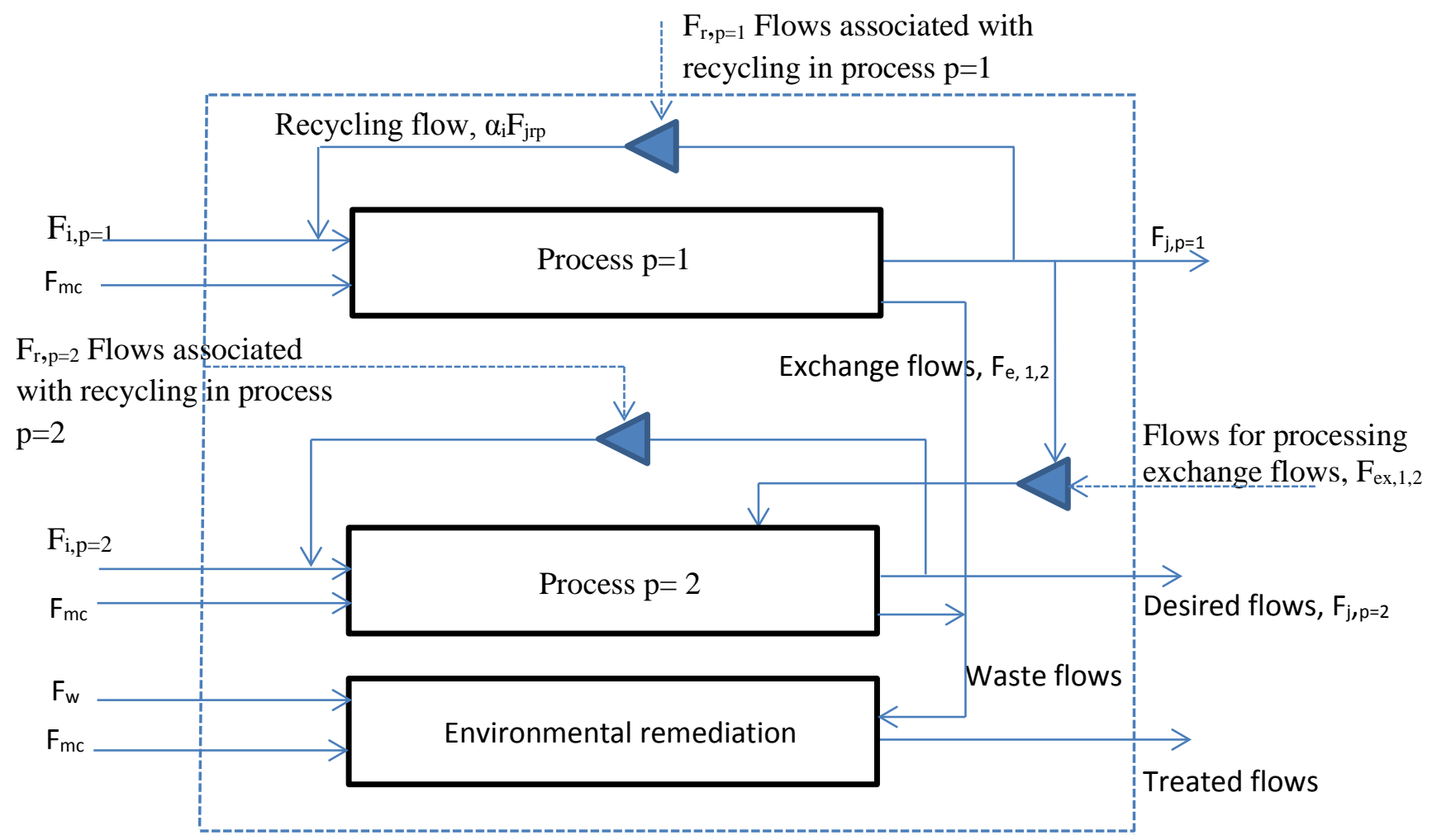

Processing of recycled or exchanged flows

\section{Boundary $\downarrow \downarrow$ Flow \\ Flows for processing recycled or exchanged flows}

Figure 4: A representation of the inter-process level

The resource accounting at the inter-process level $\left(\mathrm{ExC}_{\mathrm{ip}}\right)$ is given by the net difference between the resources incurred and gained from exchange of flows. Thus, it is given by the difference between (i) the sum of the total exergy consumption at the inter-process level 
$\left(\sum_{\mathrm{p}=1}^{\mathrm{P}} \mathrm{ExC}_{\mathrm{p}}\right)$ and the total exergy consumption of processing exchange flows $e x=1$ to $\mathrm{EX}$ at the inter-process level $\left(\sum_{\mathrm{p} \prime=1}^{\mathrm{P}} \sum_{\mathrm{p}=1}^{\mathrm{P}} \sum_{\mathrm{ex}=1}^{\mathrm{EX}} \overline{\mathrm{ExC}}_{\mathrm{ex}, \mathrm{p}, \mathrm{p},} \mathrm{F}_{\mathrm{ex}, \mathrm{p}, \mathrm{p},}\right)$ and (ii) the sum of the total exergy consumption of fresh input flows $e i=1$ to EI that the exchange flows replaced $\left(\sum_{\mathrm{p}=1}^{\mathrm{P}} \sum_{\mathrm{ei}=1}^{\mathrm{EI}} \overline{\overline{E x C}_{\mathrm{e}, \mathrm{p}}} \mathrm{F}_{\mathrm{ei}, \mathrm{p}}\right)$ and the total exergy consumption of the avoided flows enx $=1$ to ENX that would have been required for treating the discharged flows if they were not exchanged between different processes $\left(\sum_{\mathrm{enx}=1}^{\mathrm{ENX}} \overline{\mathrm{CExC}_{\mathrm{enx}}} \mathrm{F}_{\mathrm{enx}}\right)$. This accounting is expressed in Equation (5).

$$
\begin{gathered}
\mathrm{ExC}_{\mathrm{ip}}=\sum_{\mathrm{p}=1}^{\mathrm{P}} \operatorname{ExC}_{\mathrm{p}}+\sum_{\mathrm{p} \prime=1}^{\mathrm{P}} \sum_{\mathrm{p}=1}^{\mathrm{P}} \sum_{\mathrm{ex}=1}^{\mathrm{EX}} \overline{\mathrm{ExC}}_{\mathrm{ex}, \mathrm{p}, \mathrm{p}^{\prime}} \mathrm{F}_{\mathrm{ex}, \mathrm{p}, \mathrm{p},}-\sum_{\mathrm{p}=1}^{\mathrm{P}} \sum_{\mathrm{ei}=1}^{\mathrm{EI}} \overline{\mathrm{ExC}_{\mathrm{el}, \mathrm{p}}} \mathrm{F}_{\mathrm{ei}, \mathrm{p}}- \\
\sum_{\mathrm{enx}=1}^{\mathrm{ENX}} \overline{\mathrm{CExC}}_{\mathrm{enx}} \mathrm{F}_{\mathrm{enx}}
\end{gathered}
$$

Based on Equation (5), the resource benefit of exchange flows, $\eta_{\text {IPE }}$, can be expressed as the ratio of (i) the sum of the total exergy consumption of all the fresh input flows that the exchanged input flows replaced and the total exergy consumption that might be required for treating the flow if it was not exchanged, to (ii) the total exergy cost of processing any exchange flows at the inter-process level, as given in Equation (6):

$$
\eta_{\text {IPE }}=\frac{\sum_{\mathrm{p}=1}^{\mathrm{P}} \sum_{\mathrm{e}=1}^{\mathrm{EI}} \overline{\mathrm{ExC}_{\mathrm{ee}, \mathrm{p}}} \mathrm{F}_{\mathrm{ei}, \mathrm{p}}+\sum_{\mathrm{enx}=1}^{\mathrm{ENX}} \overline{\mathrm{ExC}_{\mathrm{enx}}} \mathrm{F}_{\mathrm{enx}}}{\sum_{\mathrm{p} /=1}^{\mathrm{P}} \sum_{\mathrm{p}=1}^{\mathrm{P}} \sum_{\mathrm{ex}=1}^{\mathrm{EX}} \overline{\operatorname{ExC}}_{\mathrm{ex}, \mathrm{p}, \mathrm{p}^{\prime}} \mathrm{F}_{\mathrm{ex}, \mathrm{p}, \mathrm{p}}}
$$

\subsubsection{Resource accounting at production-consumption level}

The schematic representation of the production-consumption level is shown in Figure 5 and captures the life of the desire product and/or service after it has been produced. The product can be repaired, recycled or simply disposed of after it has been consumed. 


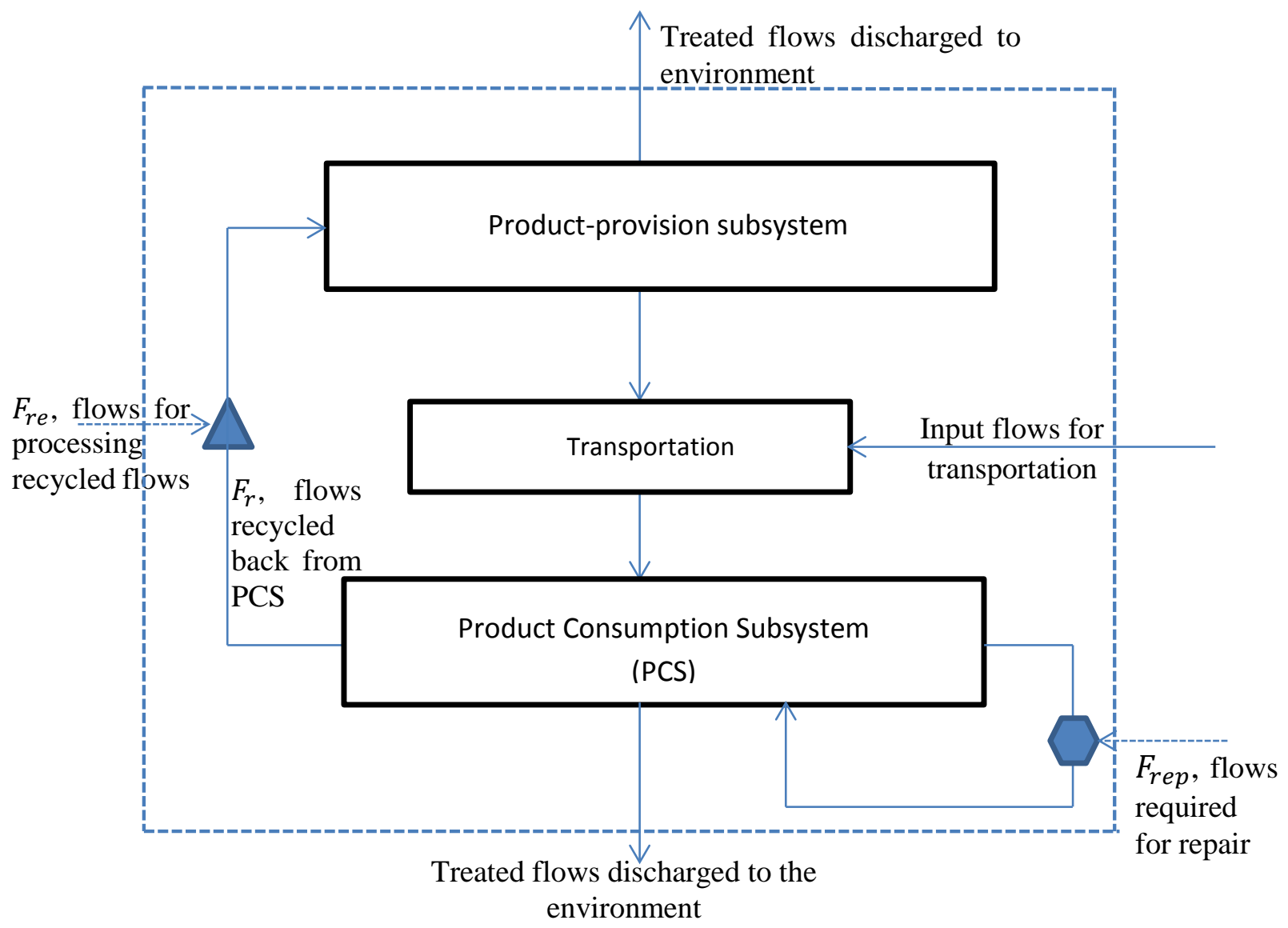

Reconditioning/Repairing for reuse

Flows for processing recycled or exchanged flows

Figure 5: A representation of the product-consumption level

As shown in Equation (7), the resource consumption at the product-consumption level, $\mathrm{ExC}_{\mathrm{pc}}$, including repair and recycling of desired products based on the boundary shown in Figure 5 can be expressed as the difference between two groups of terms. The first group, representing resource expenditures, includes (i) the total exergy consumption at the interprocess level (product-provision subsystem) $\left(\mathrm{ExC}_{\mathrm{IP}}\right)$, (ii) the total exergy resource consumption for transporting the desired products to the point of consumption (productconsumption subsystem) $\left(\sum_{\mathrm{t}=1}^{\mathrm{T}} \sum_{\mathrm{p}=1}^{\mathrm{P}} \sum_{\mathrm{j}=1}^{\mathrm{J}} \mathrm{F}_{\mathrm{j}, \mathrm{p}, \mathrm{t}} \overline{\mathrm{ExC}_{\mathrm{j}, \mathrm{p}, \mathrm{t}}}\right)$, and (iii) the total exergy resource consumption associated with (iii-a) processing of the recycled flows from the product consumption subsystem $\left(\sum_{\mathrm{rcs}=1}^{\mathrm{RCS}} \mathrm{F}_{\mathrm{rcs}} \overline{\mathrm{ExC}_{\mathrm{rcs}}}\right)$, (iii-b) processing of the repaired flows from the product consumption subsystem $\left(\sum_{\mathrm{re}=1}^{\mathrm{RE}} \mathrm{F}_{\mathrm{re}} \overline{\mathrm{ExC}_{\mathrm{re}}}\right)$, and (iii-c) resources consumed in the 
use phase of the product $\left(\sum_{\mathrm{end}=1}^{\mathrm{END}} \mathrm{F}_{\text {end }} \overline{\mathrm{ExC}}_{\mathrm{end}}\right)$. Note that the last term might include resources consumed for using the product or service, treating any effluents during product use, and end-of-life disposal. Each of these might apply to some products but not others. For instance, a washing machine consumes resources during its use, which does not apply to ethanol as a fuel. The second group, representing avoided consumptions due to resource saving measures at the production-consumption level, includes resource (i) for providing fresh flows avoided with recycling $\left(\sum_{\mathrm{rc}=1}^{\mathrm{RC}} \mathrm{F}_{\mathrm{rc}} \overline{\mathrm{ExC}_{\mathrm{rc}}}\right)$, (ii) for making a new product if it is not repaired $\left(\sum_{\mathrm{np}=1}^{\mathrm{NP}} \mathrm{F}_{\mathrm{np}} \overline{\mathrm{ExC}_{\mathrm{np}}}\right)$, and (iii) for disposing the used-products if they are not recycled back into the product provision subsystem $\left(\sum_{\mathrm{enr}=1}^{\mathrm{ENR}} \mathrm{F}_{\mathrm{enr}} \overline{\mathrm{ExC}}_{\mathrm{enr}}\right)$.

$$
\begin{gathered}
\mathrm{ExC}_{\mathrm{pc}}=\mathrm{ExC}_{\mathrm{IP}}+\sum_{\mathrm{t}=1}^{\mathrm{T}} \sum_{\mathrm{p}=1}^{\mathrm{P}} \sum_{\mathrm{j}=1}^{\mathrm{J}} \mathrm{F}_{\mathrm{j}, \mathrm{p}, \mathrm{t}} \overline{\mathrm{ExC}_{\mathrm{J}, \mathrm{p}, \mathrm{t}}}+\sum_{\mathrm{rcs}=1}^{\mathrm{RCS}} \mathrm{F}_{\mathrm{rcs}} \overline{\mathrm{ExC}_{\mathrm{rcs}}}+\sum_{\mathrm{re}=1}^{\mathrm{RE}} \mathrm{F}_{\mathrm{re}} \overline{\mathrm{ExC}_{\mathrm{re}}}+ \\
\sum_{\mathrm{end}=1}^{\mathrm{END}} \mathrm{F}_{\mathrm{end}} \overline{\mathrm{ExC}}_{\mathrm{end}}-\sum_{\mathrm{rc}=1}^{\mathrm{RC}} \mathrm{F}_{\mathrm{rc}} \overline{\mathrm{ExC}_{\mathrm{rc}}}-\sum_{\mathrm{np}=1}^{\mathrm{NP}} \mathrm{F}_{\mathrm{np}} \overline{\mathrm{ExC}_{\mathrm{np}}}-\sum_{\mathrm{enr}=1}^{\mathrm{ENR}} \mathrm{F}_{\mathrm{enr}} \overline{\mathrm{ExC}_{\mathrm{enr}}}
\end{gathered}
$$

The resource benefit of product recycling, $\eta_{\text {recycling, }}$ can be expressed as the ratio of (i) the sum of the total exergy consumption of all the fresh input flows replaced by the recycled input flows and the total exergy consumption for disposing the products if they are not recycled back into the product provision subsystem, over (ii) the total exergy consumption for product recycling; given in Equation (8)

$$
\eta_{\text {recycling }}=\frac{\sum_{\mathrm{rc}=1}^{\mathrm{RC}} \mathrm{F}_{\mathrm{rc}} \mathrm{ExC}_{\mathrm{rc}}+\sum_{\mathrm{enr}=1}^{\mathrm{ENR}} \mathrm{F}_{\mathrm{enr}} \overline{\mathrm{ExC}}_{\mathrm{enr}}}{\sum_{\mathrm{rcs}=1}^{\mathrm{RS}} \mathrm{F}_{\mathrm{rcs}} \mathrm{ExC}_{\mathrm{rcs}}}
$$

The resource benefit of product repairing $\eta_{\text {repair }}$, can be expressed as the total exergy consumption of the extended service life of the product brought by repairing, as given by Equation (9). The total exergy consumption of the extended service life can be calculated as a proportion of the total exergy consumption for the manufacture of a new product.

$$
\eta_{\text {repair }}=\frac{\text { ExC }_{\mathrm{pc}} \times \frac{\text { Extended service life }}{\text { standard service life }}}{\sum_{\mathrm{re}=1}^{\mathrm{RE}} \mathrm{F}_{\mathrm{re}} \mathrm{ExC}_{\mathrm{re}}}
$$


Table 1 gives the physical interpretation of each of the terms used in Equations (2)-(9)

Table 1: Description of the notations used in Equations (2) - (9)

\begin{tabular}{|c|c|}
\hline Notation & Description \\
\hline \multicolumn{2}{|l|}{ Equation (2) } \\
\hline $\mathrm{ExC}_{\mathrm{u}}$ & Total exergy consumption of producing a product or service at the unit $u$ level (e.g. $\mathrm{MJ} \mathrm{h}^{-1}$ ) \\
\hline$\overline{\overline{\mathrm{ExC}}_{\mathrm{i}}}$ & Specific (i.e. per unit input) exergy consumption of input $i$ (e.g. $\mathrm{MJ} \mathrm{kg}^{-1}$ ), $\mathrm{i}=1$ to I \\
\hline $\mathrm{F}_{\mathrm{i}}$ & Flow rate of input $i$ (e.g. $\mathrm{kg} \mathrm{h}^{-1}$ in the case of a material input) \\
\hline$\overline{\mathrm{ExC}}_{\mathrm{w}}$ & $\begin{array}{l}\text { Specific exergy consumption of input } w \text { for environmental remediation (e.g. } \mathrm{MJ} \mathrm{kg}^{-1} \text { ), } \mathrm{w}=1 \\
\text { to } \mathrm{W}\end{array}$ \\
\hline $\mathrm{F}_{\mathrm{w}}$ & Flow rate of input $w$ required for environmental remediation from unit $u$ (e.g. $\mathrm{kg} \mathrm{h}^{-1}$ ) \\
\hline$\overline{\mathrm{ExC}}_{\mathrm{mc}}$ & $\begin{array}{l}\text { Specific total exergy consumption of capital resources corresponding to input mc (e.g. MJ } \\
\left.\mathrm{kg}^{-1}\right), \mathrm{mc}=1 \text { to } \mathrm{MC}\end{array}$ \\
\hline $\mathrm{F}_{\mathrm{mc}}$ & Flow rate of capital resources input $m c\left(\right.$ e.g. $\mathrm{kg} \mathrm{h}^{-1}$ ) \\
\hline \multicolumn{2}{|l|}{ Equation (3) } \\
\hline $\mathrm{ExC}_{\mathrm{p}}$ & Total exergy consumption at the level of process $p$ (e.g. $\left.\mathrm{MJ} \mathrm{h}^{-1}\right)$ \\
\hline$\overline{\overline{\mathrm{ExC}_{\mathrm{r}}}}$ & $\begin{array}{l}\text { Specific total exergy consumption of all the flows } r \text { required to process the internal } \\
\left.\text { recycling flows (e.g. } \mathrm{MJ} \mathrm{kg}^{-1}\right), \mathrm{r}=1 \text { to } \mathrm{R}\end{array}$ \\
\hline $\mathrm{F}_{\mathrm{r}}$ & Flow rate of internal recycling flows $r\left(\mathrm{e} . g . \mathrm{kg} \mathrm{h}^{-1}\right)$ \\
\hline$\overline{\mathrm{ExC}_{\mathrm{Im}}}$ & Specific exergy consumption of all the intermediate flows im (e.g. $\mathrm{MJ} \mathrm{kg}^{-1}$ ), im=1 to IM \\
\hline $\mathrm{F}_{\mathrm{im}}$ & Flow rate of intermediate flows im (e.g. $\mathrm{kg} \mathrm{h}^{-1}$ ) \\
\hline$\overline{\overline{\mathrm{ExC}_{1 \mathrm{r}}}}$ & $\begin{array}{l}\text { Specific exergy consumption associated with all the fresh input flows ir replaced by the } \\
\text { recycled input flows (e.g. } \mathrm{MJ} \mathrm{kg}^{-1} \text { ), ir=1 to IR }\end{array}$ \\
\hline $\mathrm{F}_{\mathrm{ir}}$ & Flow rate of all the fresh input flows ir replaced by the recycled input flows (e.g. $\mathrm{kg} \mathrm{h}^{-1}$ ) \\
\hline$\overline{\mathrm{ExC}_{\mathrm{ac}}}$ & $\begin{array}{l}\text { Specific exergy consumption of all the flows ac that would have been required for treating } \\
\text { flows to be discharged to the environment if they were not recycled (e.g. } \mathrm{MJ} \mathrm{kg}^{-1} \text { ), ac=1 to } \\
\text { AC }\end{array}$ \\
\hline $\mathrm{F}_{\mathrm{ac}}$ & $\begin{array}{l}\text { Flow rate of flows } a c \text { that would have been required for treating flows to be discharged to } \\
\text { the environment if they were not recycled }\left(\mathrm{e} . \mathrm{g} . \mathrm{kg} \mathrm{h}^{-1}\right)\end{array}$ \\
\hline \multicolumn{2}{|l|}{ Equation (5) } \\
\hline $\mathrm{ExC}_{\mathrm{ip}}$ & Total exergy consumption at the inter-process level ip (e.g. $\mathrm{MJ} \mathrm{h}^{-1}$ ) \\
\hline$\overline{\mathrm{ExC}}_{\mathrm{ex}, \mathrm{p}, \mathrm{p} \prime}$ & $\begin{array}{l}\text { Specific exergy consumption of processing any exchange flows, ex, from process } p^{\prime} \text { to } p \text { at } \\
\text { the inter-process level (e.g. } \mathrm{MJ} \mathrm{kg}^{-1} \text { ), ex }=1 \text { to EX, } \mathrm{p}\left(\mathrm{p}^{\prime}\right)=1 \text { to } \mathrm{P}\end{array}$ \\
\hline $\mathrm{F}_{\mathrm{ex}, \mathrm{p}, \mathrm{p} \prime}$ & $\begin{array}{l}\text { Flow rate of the exchange flows, ex, from process } p \text { ' to } p \text { at the inter-process level (e.g. kg } \\
h^{-1} \text { ) }\end{array}$ \\
\hline$\overline{\mathrm{ExC}}_{\mathrm{ei}, \mathrm{p}}$ & $\begin{array}{l}\text { Specific exergy consumption of fresh input flows, ei, that the exchange flows replaced for } \\
\text { process } p\left(\text { e.g. } \mathrm{MJ} \mathrm{kg}^{-1}\right) \text {, ei=1 to EI, } \mathrm{p}=1 \text { to } \mathrm{P}\end{array}$ \\
\hline $\mathrm{F}_{\mathrm{ei}, \mathrm{p}}$ & $\begin{array}{l}\text { Flow rate of the fresh input flows } e i \text { that the exchange flows replaced for process } p \text { (e.g. kg } \\
h^{-1} \text { ) }\end{array}$ \\
\hline$\overline{\mathrm{ExC}}_{\mathrm{enx}}$ & $\begin{array}{l}\text { Specific exergy consumption of flows enx that would have been required for treating the } \\
\text { discharged flows if they were not exchanged between different processes (e.g. } \mathrm{MJ} \mathrm{kg}^{-1} \text { ), } \\
\text { enx= } 1 \text { to ENX }\end{array}$ \\
\hline $\mathrm{F}_{\mathrm{enx}}$ & $\begin{array}{l}\text { Flow rate of avoided input flows enx that would have been required for treating the } \\
\text { discharged flows if they were not exchanged between different processes (e.g. } \mathrm{kg} \mathrm{h}^{-1} \text { ) }\end{array}$ \\
\hline \multicolumn{2}{|l|}{ Equation (7) } \\
\hline$\overline{\mathrm{ExC}}_{\mathrm{j}, \mathrm{p}, \mathrm{t}}$ & $\begin{array}{l}\text { Specific exergy consumption associated with transport } t \text { of final products } j \text { from process } p \\
\left(\text { e.g. } \mathrm{MJ} \mathrm{kg}^{-1}\right), \mathrm{j}=1 \text { to } \mathrm{J}, \mathrm{p}=1 \text { to } \mathrm{P}, \mathrm{t}=1 \text { to } \mathrm{T}\end{array}$ \\
\hline
\end{tabular}




\begin{tabular}{|c|c|}
\hline $\mathrm{F}_{\mathrm{j}, \mathrm{p}, \mathrm{t}}$ & Flow rate of input flows required for transportation $t$ of output $j$ from process $p\left(\right.$ e.g. $\mathrm{kg} \mathrm{h}^{-1}$ ) \\
\hline$\overline{\mathrm{ExC}}_{\mathrm{rcs}}$ & $\begin{array}{l}\text { Specific exergy consumption associated with the input flows } r c s \text { required for processing of } \\
\text { the recycled flows from the consumption subsystem (e.g. } \mathrm{MJ} \mathrm{kg}^{-1} \text { ), rcs }=1 \text { to RCS }\end{array}$ \\
\hline $\mathrm{F}_{\mathrm{rcs}}$ & $\begin{array}{l}\text { Flow rate of input flows } r c s \text { required for processing of the recycled flows from the } \\
\text { consumption subsystem }\left(\text { e.g. } \mathrm{kg} \mathrm{h}^{-1}\right)\end{array}$ \\
\hline$\overline{\mathrm{ExC}}_{\mathrm{re}}$ & $\begin{array}{l}\text { Specific exergy consumption of input flows re required for the processing of the repair } \\
\left.\text { flows from the consumption subsystem (e.g. } \mathrm{MJ} \mathrm{kg}^{-1}\right), \mathrm{re}=1 \text { to } \mathrm{RE}\end{array}$ \\
\hline $\mathrm{F}_{\mathrm{re}}$ & $\begin{array}{l}\text { Flow rate of the input flows re required for the processing of the repair flows from the } \\
\left.\text { consumption subsystem (e.g. } \mathrm{kg} \mathrm{h}^{-1}\right)\end{array}$ \\
\hline$\overline{\mathrm{ExC}}_{\mathrm{rc}}$ & $\begin{array}{l}\text { Specific exergy consumption associated with fresh flows } r c \text { avoided with recycling (e.g. MJ } \\
\left.\mathrm{kg}^{-1}\right), \mathrm{rc}=1 \text { to RC }\end{array}$ \\
\hline $\mathrm{F}_{\mathrm{rc}}$ & Flow rate of fresh flows $r c$ avoided with recycling (e.g. $\mathrm{kg} \mathrm{h}^{-1}$ ) \\
\hline$\overline{\mathrm{ExC}_{\mathrm{np}}}$ & $\begin{array}{l}\text { Specific exergy consumption of flows } n p \text { required for making a new product if it is not } \\
\text { repaired (e.g. MJ kg-1), np = } 1 \text { to NP }\end{array}$ \\
\hline $\mathrm{F}_{\mathrm{np}}$ & $\begin{array}{l}\text { Flow rate of flows input } n p \text { required for making a new product if it is not repaired (e.g. } \mathrm{kg} \mathrm{h}^{-} \\
{ }^{1} \text { ) }\end{array}$ \\
\hline$\overline{\mathrm{ExC}}_{\text {end }}$ & $\begin{array}{l}\text { Specific exergy consumption of all the flows end consumed in the use and end-of-life } \\
\text { phases of the product (e.g. } \mathrm{MJ} \mathrm{kg}^{-1} \text { ), end }=1 \text { to END }\end{array}$ \\
\hline $\mathrm{F}_{\text {end }}$ & $\begin{array}{l}\text { Flow rate of input flows end consumed in the use and end-of-life phases of the product (e.g. } \\
\mathrm{kg} \mathrm{h}^{-1} \text { ) }\end{array}$ \\
\hline$\overline{\mathrm{ExC}}_{\mathrm{enr}}$ & $\begin{array}{l}\text { Specific exergy consumption of flows enr for disposing the products if they are not recycled } \\
\text { back into the product provision subsystem (e.g. MJ kg }{ }^{-1} \text { ), enr=1 to ENR }\end{array}$ \\
\hline $\mathrm{F}_{\mathrm{enr}}$ & $\begin{array}{l}\text { Flow rate of input flows enr used for disposing the products if they are not recycled back } \\
\text { into the product provision subsystem (e.g. } \mathrm{kg} \mathrm{h}^{-1} \text { ) }\end{array}$ \\
\hline
\end{tabular}

\subsection{Summary of the resource accounting framework}

In this section, we have presented a holistic and comprehensive framework for assessing resource consumption in industrial production processes and their interactions with the environment and the consumption system, with the following key elements:

(1) At the starting point, a conceptual framework introduces fundamental concepts such as system, flow, process and environment. Various types of resource flows, such as material, energy and human labour are considered. Resource-generating processes are distinguished into Type-I and Type-II processes, to allow appropriate resource accounting principles to be applied to flows originated from these processes. Resource consumption by processes for both production and environmental remediation is taken into account.

(2) With the basic concepts introduced above, a multi-level structure is presented for resource accounting at different technical levels, which include unit, process, inter- 
process, and production-consumption, with intra-level and inter-level connections specified.

(3) Finally, a resource accounting algebra is formulated according to the multi-level structure, offering key equations for quantitatively assessing different design options at different levels. It also proposes quantities to support the evaluation of important resource decisions such as intra-level recycling, inter-level exchange, and repair and recycling of used products.

\section{An illustrative example-bioethanol production}

The approach developed for resource accounting is illustrated through a case study on the production and consumption of ethanol from sugarcane for a typical plant with a capacity of 50,000 tonnes of ethanol per year, as shown in Figure 6. Biofuels have been advocated as an important alternative for energy supply especially as a substitute for fossil fuels (Pereira and Ortega, 2010) and Brazil is one of biggest ethanol producer in the world and produces most of its ethanol from sugarcane. The increase in the demand for biofuel as a renewable substitute for gasoline has intensified the need for more efficient means of production (Dias et al., 2010). As such, the analysis of ethanol production and the identification of key components that could potentially lead to huge reductions in resource consumption are required. The case study illustrates how natural (e.g. photosynthesis), agricultural (e.g. cane cultivation) and industrial (e.g. ethanol plant) processes as well as the consumption of the final product can be included in the resource accounting at different system levels.

The basis of the resource accounting is the production/consumption of one tonne of ethanol. As a simplified illustration of the developed method, the resource accounting does not include land use for the ethanol plant as well as the resources used for site development and plant installation. Labour for industrial manufacture of ethanol has also not been accounted. 
On the environmental remediation resource consumption, only those for treating vinasse, carbon dioxide emissions and methane emissions resulting from bagasse decomposition have been considered.

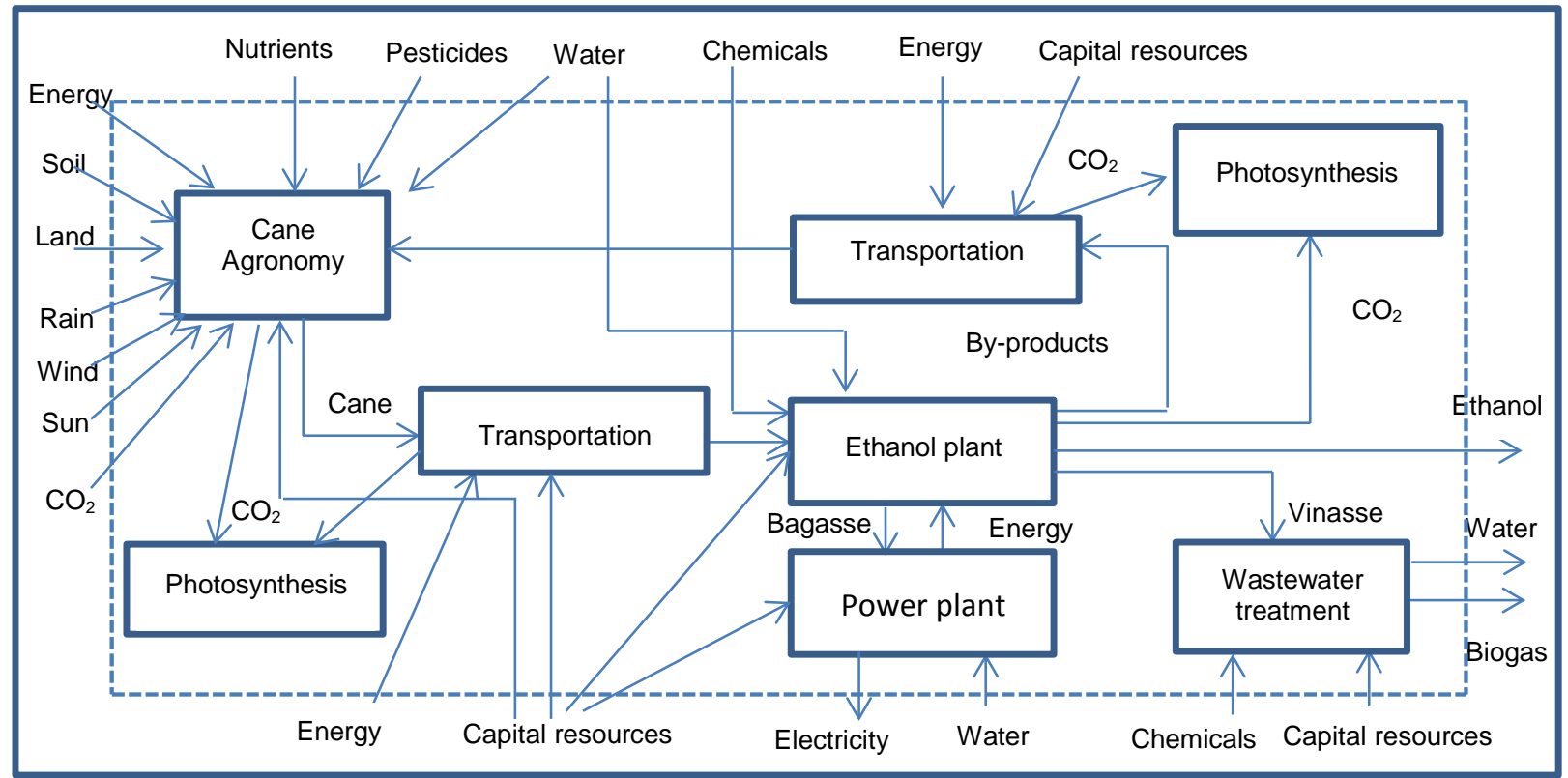

Figure 6: The case study on ethanol production from cane

Data for this case study have been taken mainly from studies on exergy consumption from sugarcane ethanol carried out by Bastianoni and Marchettini (1996) and Palacios-Bereche et al. (2012, 2013) together with the cumulative exergy database developed by Szargut et al. (1988), which are adapted to the framework and the system boundary considered in this study.

\subsection{Resource accounting at various levels}

Sections 3.1.1 to 3.1.4 summarise the results of the application of the multilevel framework on the case study on ethanol production and consumption at the different levels of analysis. Detailed calculations are provided in the Supporting Information. 


\subsubsection{Resource accounting at unit level}

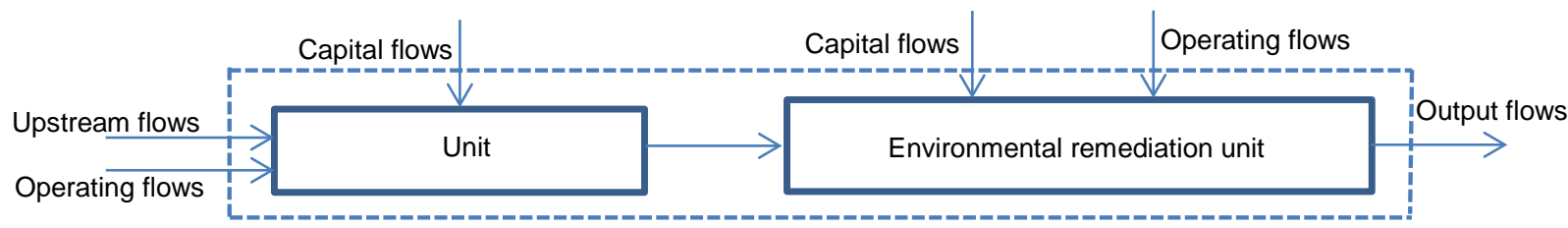

Figure 7: Ethanol production at the unit level

Figure 7 represents resource accounting at the unit level. A unit could be cane agronomy, cane transportation, cane milling, cane juice clarification, fermentation, distillation, dehydration, distribution, and consumption of ethanol. The resource accounting algebra is illustrated here at the unit level to assess two alternative technologies for ethanol dehydration, namely molecular sieve and azeotropic distillation. Using Equation (2) for resource accounting at the unit level, the total exergy resource consumption for the dehydration of hydrous ethanol to anhydrous ethanol using azeotropic distillation was determined to be $5.86 \times 10^{3} \mathrm{MJ} /$ tonne ethanol more than that for molecular sieve distillation. Though, the CEC of the upstream flows to both the molecular sieve and azeotropic distillation unit was similar, the CEC of the operating resources (i.e. steam) and capital resources in terms of equipment required for azeotropic distillation were found to be respectively 2.8 and 1.3 times higher than that for molecular sieve. Moreover, azeotropic distillation uses cyclohexane as a consumable with a CEC of $478 \mathrm{MJ} /$ tonne ethanol.

\subsubsection{Resource accounting at process level}

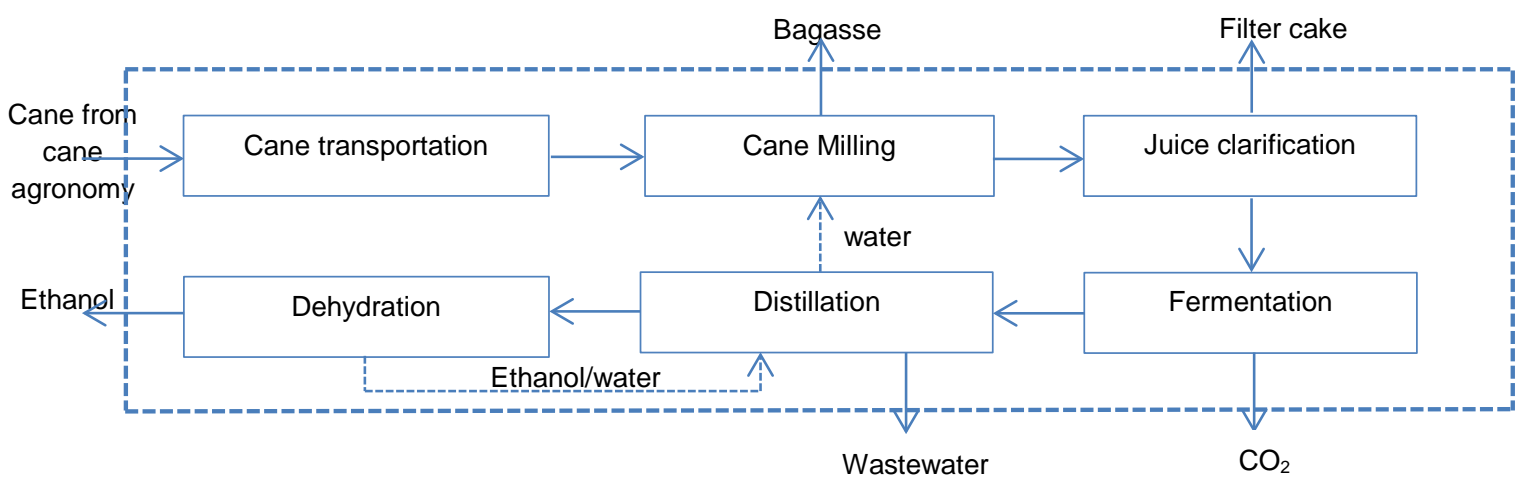

Figure 8: Ethanol production system at the process level 
Figure 8 illustrates the production of ethanol at the process level without any intra-process recycling flows. At this level, the resource accounting algebra is used to assess a) the recycling of water flows from the distillation unit to be used as imbibition water for cane milling to reduce freshwater consumption and b) the recycling of reject flow (containing mostly water and residual ethanol) from the molecular sieve dehydration units to the distillation unit to recover more ethanol and thus reduce the amount of cane processed to produce the same amount of final ethanol product. However, the recycled flows might require some processing before being pumped back as input flows to a unit. Consequently, a proper resource accounting at the process level can determine if intra recycling flows will have a positive impact overall on resource consumption.

The ethanol/water flow from the regeneration bed can replace about $15 \%$ of the ethanol from the fermentation beer; leading to a saving of $15 \%$ on all the resources used before the distillation unit. Part of the water produced from the distillation unit can be recycled back internally to the cane milling unit to fully satisfy its imbibition water requirements. Using Equation (3) for resource accounting at the process level, it was determined that it would be possible to reduce the total exergy resource consumption for the production of ethanol by $1.23 \times 10^{4} \mathrm{MJ} /$ tonne ethanol through the implementation of these internal recycling flows.

\subsubsection{Resource accounting at inter-process level}

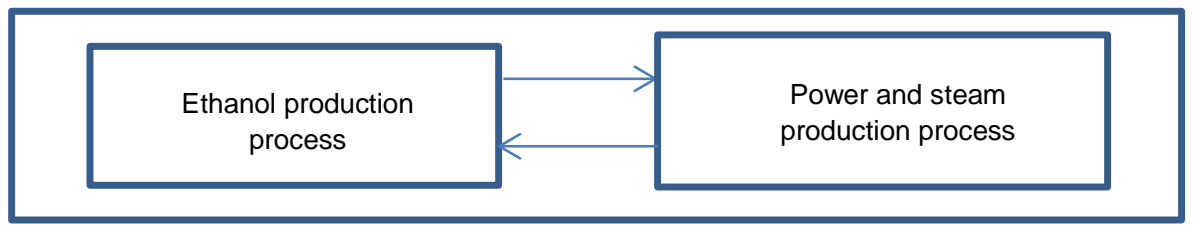

Figure 9: Production of ethanol at the inter-process level

Figure 9 illustrates the production of ethanol at the inter-process level with exchange and recycled flows. At the inter-process level, synergies between different types of processes; including heterogeneous processes like ecological and technological processes, can be 
investigated and their overall impact on resource consumption determined. For ethanol production, the bagasse produced as a by-product of cane milling can be considered as a useful resource and can be exchanged with the power plant so as to produce the steam and electricity required by the ethanol plant. Using Equation (5) for resource accounting at the inter-process level, it was inferred that an additional resource saving of $8.88 \times 10^{4} \mathrm{MJ} /$ tonne ethanol could be achieved by implementing exchange flows together with the internal recycling flows.

\subsubsection{Resource accounting at production-consumption level}

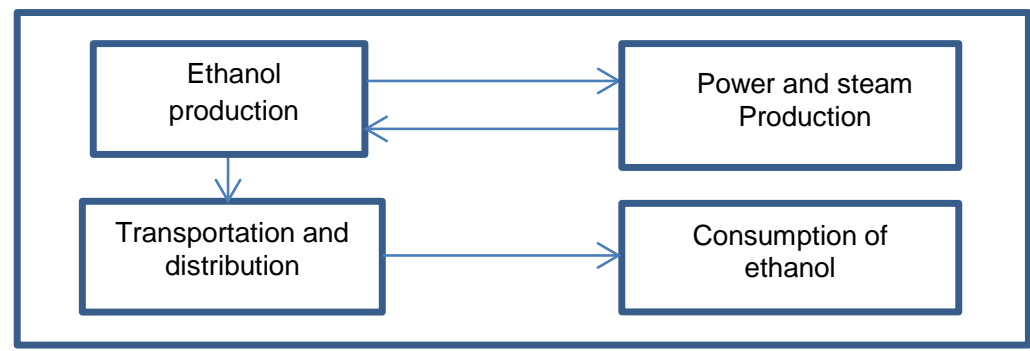

Figure 10: The interaction between production and consumption of ethanol

Figure 10 shows the overall system of production and consumption of ethanol with exchange and recycled flows. In principle, the resource benefit of practices that can potentially promote sustainable consumption such as product recycling and repair after the product has been consumed can be investigated at this level. However, ethanol is an immediate product of consumption; and as such repair or recycling of ethanol is not applicable in this case. The consumption unit for the ethanol case study would include upstream resource flows for ethanol production, resources required for the environmental remediation of harmful emissions (i.e. carbon dioxide) released during ethanol transportation from the ethanol plant to fuelling stations and from ethanol combustion in vehicles; capital resources for manufacturing the distribution infrastructures; and operating resources (i.e. diesel) used for ethanol transportation in tank cars. Using Equation (7) for resource accounting at the production-consumption level, the total exergy consumption for ethanol production and 
consumption was determined to be $1.26 \times 10^{4} \mathrm{MJ} /$ tonne ethanol excluding exergy flows from Type-II processes.

\subsection{Comparative analysis}

The impacts of intra-process recycling and inter-process exchange of flows on resource consumption have been further illustrated and analysed in three different scenarios. The $1^{\text {st }}$ scenario analyses the production and consumption of ethanol without any recycling flows. The $2^{\text {nd }}$ scenario is on the production and consumption of ethanol from cane using intrarecycling flows, i.e. recycled water flows from the distillation unit to be used as imbibition water for cane milling and recycled ethanol/water flows from the molecular sieve dehydration units to the distillation unit. It is assumed that these intra-recycling flows do not require any processing before being used. In both the $1^{\text {st }}$ and $2^{\text {nd }}$ scenarios, energy is supplied externally and bagasse, the by-product of cane milling, is not used. The $3^{\text {rd }}$ scenario analyses the significance of using exchange and recycling flows, including the use of bagasse for energy supply. It is assumed in the $3^{\text {rd }}$ scenario that the bagasse exchange flow does not require any processing prior to being used in the power station.

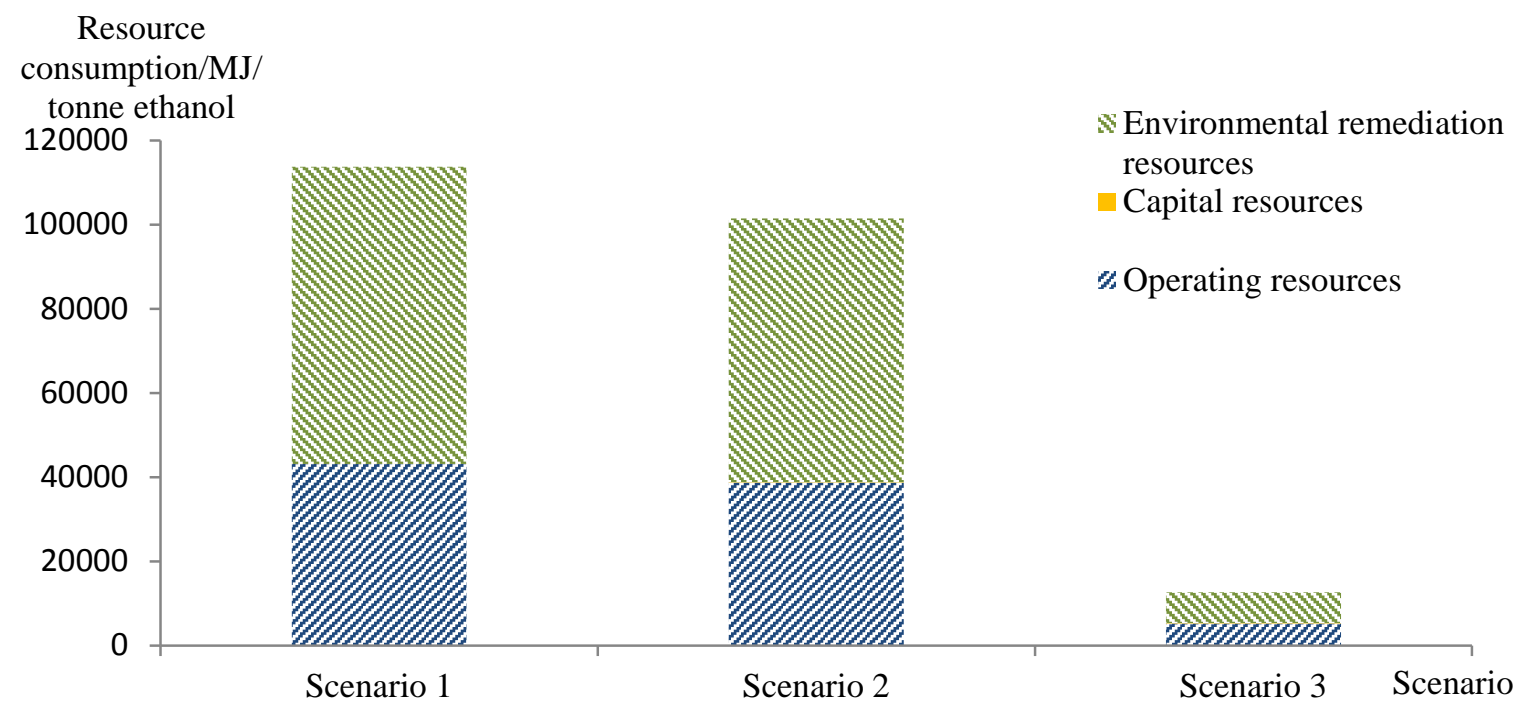

Figure 11: Overall resource consumption for the three scenarios excluding Type-II flows 
The total exergy flows from Type-II processes and Type-I processes were of different orders of magnitude. For cane agronomy, the total operating exergy flows in terms of exergy content from Type-II processes (e.g. sunlight, wind and land use for cane agronomy) was estimated to be approximately $1.33 \times 10^{7} \mathrm{MJ} /$ tonne ethanol as compared to the total operating exergy flows from Type-I processes determined to be about $2.76 \times 10^{3} \mathrm{MJ} /$ tonne ethanol based on cumulative exergy consumption for the $1^{\text {st }}$ scenario. Due to this huge disparity, the combination of these two types of flows would hinder a practical analysis of the modifications done mainly to improve performance within the boundary of the sugarcane processing, which involves flows from Type-I processes only. Therefore, the detailed resource consumption analysis focus primarily on flows from Type-I processes. Figure 11 shows an overall comparison of resource consumption for the three different scenarios excluding flows from Type-II processes. It can be observed that environmental remediation accounts for most of the resource consumption followed by operating resources and capital resources.

The resource consumption from environmental remediation is relatively high in both the $1^{\text {st }}$ and $2^{\text {nd }}$ scenarios as bagasse is considered as a waste and is simply disposed of. It was determined that it would incur about $1.00 \times 10^{5} \mathrm{MJ} /$ tonne ethanol of cumulative exergy consumption to treat the methane emissions generated from decomposition of bagasse. Using global warming impact factors, the $\mathrm{CO}_{2}$ equivalent emission was determined and it was assumed that such amount of $\mathrm{CO}_{2}$ is absorbed using photosynthesis. In the $3^{\text {rd }}$ scenario, the use of bagasse for energy production led to a $90 \%$ decrease in environmental remediation resource consumption as compared to the $1^{\text {st }}$ scenario. This is because carbon dioxide released during bagasse burning requires 25 times less resources for environmental remediation than methane emissions. The operating resource consumption in the $3^{\text {rd }}$ scenario has decreased by $90 \%$ as compared to the $1^{\text {st }}$ scenario. This is mainly because the total 
resource consumption for ethanol production is now being shared with bagasse with an allocation factor of 0.507 based on exergy content. Besides, the energy requirements of the ethanol plant, which contribute to most of its operating resource consumption, are now being fully satisfied by steam and electricity from the combustion of the bagasse exchange flow in the power station. In addition, the surplus electricity generated from bagasse burning in the power station has an overall positive impact on resource consumption for ethanol production. The surplus electricity is a valuable resource that can be exported to the grid and hence the resource consumption for ethanol produced from the ethanol plant is now shared with the surplus electricity with an exergy based allocation factor of 0.887 .

Capital resources have negligible contribution to the cumulative exergy consumption for the three scenarios. The $3^{\text {rd }}$ scenario has slightly higher capital resource cost than the other two scenarios especially due to capital resource consumption associated with the power station. The capital burdens of plant equipment, machineries and transportation vehicles have been estimated by spreading the total cumulative exergy consumption for their capital resources to unit output. The high usage factor of plant equipment and an assumed operational life span of 15 years for the agricultural machinery, plant equipment and transportation vehicles have led to negligibly low capital resource consumption compared to the operating and environmental remediation resource consumption.

\section{Conclusions}

The application of the proposed multilevel resource accounting framework on this case study on ethanol production and consumption from sugarcane proved to be useful in illustrating how the framework can help to assess the full effects on resource efficiency for design decisions at all levels, allowing design options to be explored to find the most efficient option. The proposed framework has provided powerful insights into how reduction/increase 
of resource consumption can occur at different levels. It also offers the potential to identify key components and flows that can be either removed or improved through integration and linkage with other flows or components in the system. More specifically, its structural depiction through a multi-level view is able to reveal how a resource, before and after being processed at different levels, flows within the totality of the environment and system. By explicitly accounting for all types of resources including operating and capital resources, environmental remedial resources, labour and ecological goods and services, this method can be used as an insightful tool for evaluating resource utilisation and consumption. The proposed approach can be useful in providing support for decision making at the technical level of interest to process engineers and strategic planners in a wide range of organisations. However, it can also be adapted and applied in other areas: apart from resource consumption, other indicators could be used with the developed multilevel framework. On-going work involves developing a method for optimal design of local production systems where resource consumption is used as an objective function to be optimised and as an indicator to guide the design or retrofit. On the other hand, practical limitations such as incompleteness and uncertainties associated with data collection may prevent the framework from being meaningful when applied on much larger scale systems. Furthermore, the framework as it currently stands does not address resource sufficiency or scarcity. These are important challenges that will be addressed in future work.

\section{Acknowledgments}

Financial support from the Leverhulme Trust is gratefully acknowledged. 


\section{References}

Allwood, J.M, Ashby, M.F, Gutowski, T.G., Worrell, E., 2011. Material efficiency: a white paper. Resour. Conserv. Recycl. 2011, 55(3):362-81.

Amini, S.H., Remmerswaal, J.A.M., Castro, M.B., Reuter, M.A., 2006. Quantifying the quality loss and resource efficiency of recycling by means of exergy analysis. J of Clean. Prod. 15 (2007) 907-913

Baral, A., Bakshi, B.R., Smith, R.L., 2012. Assessing resource intensity and renewability of cellulosic ethanol technologies using eco-LCA. Environ. Sci. Technol. 46, 2436-2444.

Bastianoni, S., Marchettini, N., 1996. Ethanol production from biomass: Analysis of process efficiency and sustainability. Biomass Bioenergy. Vol. 11, No. 5, pp. 411-418, 1996

Brown, M.T., Ulgiati, S., 2010. Updated evaluation of exergy and emergy driving the geobiosphere: a review and refinement of the emergy baseline. Ecol. Modell. 221, 2501-2508.

BSI, 2008. PAS 2050 (2008) - Specification for the assessment of the life cycle greenhouse gas emissions of goods and services, British Standards Institution

Chertow, M., 2007. Uncovering Industrial Symbiosis. J. Ind. Ecol. 11.1 (2007): 11-30. DOI: 10.1162/jiec.2007.1110

Department for Environment Food and Rural Affairs (DEFRA), 2014. Energy from waste - A guide to the debate [Online], Available from: 
https://www.gov.uk/government/uploads/system/uploads/attachment_data/file/284612/pb141 30-energy-waste-201402.pdf, [Accessed 28 December 2015]

Dewulf, J., Bosch, M.E., Demeester, B., Vandervorst, G., Vanlangenhove, H,. Hellweg, S., and Huijbregts, M.A., 2007. Cumulative Exergy Extraction from the Natural Environment (CEENE): a comprehensive Life Cycle Impact Assessment method for resource accounting. Environ. Sci. Technol. 41, 8477-8483

Dias, M, O, S., Cunha, M.P., Jesus, C.D.F., Scandiffio, M.I.G., Rossella, C.E.V., Filho, R.M., Bonomia, A., 2010. Simulation of ethanol production from sugarcane in Brazil: economic study of an autonomous distillery, $20^{\text {th }}$ European Symposium on Computer Aided Process Engineering- ESCAPE20, 6-9 June 2010, Naples, Italy

Ellen Macarthur Foundation, 2013. The Circular Model e Brief History and School of $\begin{array}{llll}\text { Thought } & \text { [Online], from: }\end{array}$ http://www.ellenmacarthurfoundation.org/circulareconomy/circular-economy/the-circularmodel-brief-history-and-schools-ofthought, [Accessed 29 December 2015]

European Commission (EC), 2013. Online Resource Efficiency Platform (OREP) [Online], Available from: http://ec.europa.eu/environment/resource_efficiency/ [Accessed 20 November 2013]

Gaudreau, K., 2009. Exergy Analysis and Resource Accounting, Master Thesis, University of Waterloo, Ontario, Canada 
Guinée, J.B., Gorree, M., Heijungs, R., Huppes, G., Kleijn, R., Udo deHaes, H.A., Van der Voet, E., Wrisberg, M.N., 2002. Handbook on Life Cycle Assessment. An Operational Guide to the ISO Standards, Centre of Environmental Science, Leiden University, Leiden, The Netherlands.

Hanes, R. J., Bakshi, B. R., 2015a. Process to planet: A multiscale modeling framework toward sustainable engineering. AIChE J. DOI: 10.1002/aic.14919

Hanes, R. J., Bakshi, B. R., 2015b. Sustainable process design by the process to planet framework. AIChE J. DOI: 10.1002/aic.14918

Hau, J., Bakshi, B., 2004. Expanding Exergy Analysis to Account for Ecosystem Services and Products. Environ. Sci. Technol. 2004, 38, 3768-3777

Huijbregts, M.A.J., Hellweg, S., Frischknecht, R., Hendriks, H.W.M., Hungerbuhler, K., Hendriks, A.J., 2010. Cumulative energy demand as predictor for the environmental burden of commodity production. Environ Sci Technol. 44:2189-2196

Jawad, H., Jaber, M.Y., Bonney, M., 2015. The Economic Order Quantity model revisited: an Extended Exergy Accounting approach. J of Clean. Prod. 105 (2015) 64-73

Jorgensen, S.E., 1997. Integration of Ecosystem Theories: a Pattern; Kluwer Academic Publishers: Boston, MA

International Standardisation Organisation (ISO), 2005. ISO 9000:2005(en) Quality management systems-Fundamentals and vocabulary [Online], Available from: https://www.iso.org/obp/ui/\#iso:std:iso:9000:ed-3:v1:en, [Accessed 28 December 2015] 
International Standardisation Organisation (ISO), 2006. ISO 14040:2006(en) Environmental management-Life cycle assessment-Principles and framework [Online], Available from: https://www.iso.org/obp/ui/\#iso:std:iso:14040:ed-2:v1:en [Accessed 28 December 2015]

Krautkraemer, J., 2005. Economics of Natural Resource Scarcity: The State of the Debate [Online], Available from http://www.rff.org/files/sharepoint/WorkImages/Download/RFFDP-05-14.pdf, [Accessed 24 December 2015]

Kotas, T., 1985. The exergy method of thermal plant analysis. London: Butterworths, 1985

Liao, W., Heijungs, R., Huppes, G., 2012. Thermodynamic resource indicators in LCA: a case study on the titania produced in Panzhihua city, southwest China. Int J Life Cycle Assess. (2012) 17:951-961

Moller, H., 2010. Environmental Impacts from Capital Goods in LCA of Meat Products Bari: LCA Food; 2010

Odum, H.T., 1996. Environmental Accounting: Emergy and Environmental Decision Making. John Wiley \& Sons, New York, USA

Palacios-Bereche, R., Mosqueira-Salazar, K.J., Modesto, M., Ensinas, A., Nebra,A., Serra,L., Lozano, M., 2012. Exergetic analysis of the ethanol production by enzymatic hydrolysis process from sugarcane biomass. $3^{\text {rd }}$ International Conference on Contemporary Problems of Thermal Engineering CPOTE 2012. 18-20 September 2012, Gliwice, Poland Institute of Thermal Technology 
Palacios-Bereche, R, Mosqueira-Salazar, K.J., Modesto, M., Ensinas, A., Nebra,A., Serra,L., Lozano, M., 2013. Exergetic analysis of the integrated first- and second-generation ethanol production from sugarcane. Energy. 62 (2013) 46-61

Pereira, C.L.F., and Ortega, E., 2010. Sustainability assessment of large-scale ethanol production from sugarcane. J of Clean. Prod. 18 (2010) 77-82

Rocco, M.V., Colombo, E., Sciubba, E., 2013. Advances in exergy analysis: a novel assessment of the Extended Exergy Accounting Method. Appl. Energy. 113 (2014) 1405-1420

Rocco, M.V., Cassetti, G., Gardumi, F., Colombo, E., 2015. Exergy Life Cycle Assessment of soil erosion remediation technologies: an Italian case study. J of Clean. Prod. 112 (2016) 30073017

Sciubba, E., 2001. Beyond thermoeconomics? the concept of extended exergy accounting and its application to the analysis and design of thermal systems. Exergy: Int. J. 1 (2), 68-84.

Ukidwe, N.U., Bakshi, B.R., 2004. Thermodynamic accounting of ecosystem contribution to economic sectors with application to 1992 U.S. economy. Environ Sci Technol. 15; 38(18):4810-27

United Nations Environment Programme (UNEP), 2012. Global Outlook on Sustainable Consumption and Production Policies: Taking action together [Online], Available from: http://www.unep.fr/shared/publications/pdf/DTIx1498xPAGlobalOutlookonSCPPolicies.pdf, [Accessed 28 November 2013] 
United States Census Bureau (USCB), 2013. U.S and World Population Clock [Online], Available from: http://www.census.gov/popclock/ [Accessed 10 December 2013]

Wall, G., 2002. Conditions and tools in the design of energy conversion and management systems of a sustainable society. Energy Convers. Manage. 43 (2002) 1235-1248.

Wall, G., 2011. Tools for Sustainable Energy Engineering, World Renewable Energy Congress 2011-Sweden

Yang, Z.F., Jiang, M.M., Chen, B., Zhou, J.B., Chen, G.Q., Li, S.C., 2010. Solar emergy evaluation for Chinese economy. Energy Policy. 39, 875-886.

Yang, S., Yang, S., Qian, Y., 2015. The inclusion of economic and environmental factors in the ecological cumulative exergy consumption analysis of industrial processes. $J$ of Clean. Prod. 108 (2015) 1019-1027

Yi, H-S., Hau, J.L., Ukidwe, N.U., Bakshi, B.R., 2004. Hierarchical Thermodynamic Metrics for Evaluating the Environmental Sustainability of Industrial Processes. Environ Prog. Vol.23, No.4, DOI: 10.1002/ep.10049

Zhang, Y., Singh, S., Bakshi, B. R., 2010. Accounting for Ecosystem Services in Life Cycle Assessment, Part I: A Critical Review. Environ Sci Technol. 44, 7, 2232-2242 